\title{
CYTOHISTOLOGIC CORRELATION OF LUNG SPACE OCCUPYING LESIONS (SOL)- A STUDY OF 72 CASES IN A TERTIARY CARE HOSPITAL
}

\author{
Pratyusha Bhattacharjee1, Himansu Roy², Partha Pratim Sinha Roy3 \\ ${ }^{1}$ Specialist Medical Officer, Department of Pathology, Siliguri District Hospital, Darjeeling. \\ ${ }^{2}$ Associate Professor, Department of Surgery, Medical College, Kolkata. \\ 3Specialist Medical Officer, Department of General Surgery, Mal Super Speciality Hospital, Jalpaiguri.
}

ABSTRACT
BACKGROUND
Lung carcinoma is one of the commonest malignancies with high mortality and morbidity. Recent epidemiological studies indicate
increasing incidence of lung carcinoma in India. The objectives of the study were to evaluate the clinico-pathological profile of
patients of lung carcinoma in a tertiary care hospital and to correlate between cytological and histological diagnoses of the
tumours.

\section{MATERIALS AND METHODS}

A study of patients presenting with lung mass between March 2016 and February 2017 (one year) was performed. Guided fine needle aspiration cytology (FNAC) was performed in each case and core needle biopsy was done whenever feasible.

Statistical Analysis Used- The data was compiled using Microsoft Word Excel 2007. Kappa statistic test and percentage agreement was done and Kappa coefficient was derived.

Study Settings and Design- It was a descriptive type of study.

\section{RESULTS}

A total of 72 patients were included. The ratio of male-to-female patients was 6: 1 . The age of the patients ranged between 41 and 82 years with preponderance in age group of 61 - 70 years (44.4\%). Computed tomography (CT) guided FNAC was done in all cases. Non-neoplastic lesions were found in $8(11.11 \%)$ and neoplastic lesions in $64(88.88 \%)$ cases. Among the neoplastic lesions, adenocarcinoma was diagnosed in 34 cases (62.96\%), squamous cell carcinoma in 14 (25.92\%), metastatic lesion in 5 (9.26\%) and neuroendocrine carcinoma in 1 case (1.85\%). Fifty (78.1\%) patients of lung carcinoma were smokers. The right lung was involved in $38(60 \%)$, the left in $19(30 \%)$ and both lungs in $7(10 \%)$ cases. Core needle biopsy was undertaken in 43 cases. Consistent histopathologic findings were obtained in 40 cases.

\section{CONCLUSION}

Smoking constitutes an important, yet avoidable cause of lung carcinoma. The delineation of clinico-pathologic profile of patients of a particular area is essential for determination of preventive and therapeutic strategies. FNAC can be considered as a highly useful tool for diagnosis of lung mass.

\section{KEYWORDS}

Cyto-Histologic Correlation, Lung SOL.

HOW TO CITE THIS ARTICLE: Bhattacharjee P, Roy H, Roy PPS. Cytohistologic correlation of lung space occupying lesions (SOL)- a study of 72 cases in a tertiary care hospital. J. Evolution Med. Dent. Sci. 2018;7(03):321-323, DOI: 10.14260/jemds/2018/71

\section{BACKGROUND}

Lung cancer is one of the leading causes of death of millions of people in today's world. According to an epidemiological study, the prevalence of lung cancer is rising in Indian population compared to the western countries. ${ }^{[1]}$ The inciting factor is smoking in most cases.[2,3] Histopathologically, cell types may vary with the changes of social and other environmental factors. ${ }^{[4]}$

According to the first population-based cancer registry (PBCR) from eastern part of India published in 2002, highest number of lung cancer cases among males has been

'Financial or Other Competing Interest': None.

Submission 09-12-2017, Peer Review 03-01-2018,

Acceptance 09-01-2018, Published 13-01-2018.

Corresponding Author:

Dr. Pratyusha Bhattacharjee,

Cedar Apartment, Second Floor

Ramthakur Mandir Road,

New Milan Pally, Ward No. 25,

Siliguri, District-Darjeeling-734005, West Bengal.

E-mail: pratyushabhattacharya57@gmail.com

DOI: $10.14260 /$ jemds $/ 2018 / 71$ documented from West Bengal compared to other regions of India. Lung cancer is the most common cancer in males $(16.3 \%)$ and the fifth common in females $(3.9 \%)$ in West Bengal.[5]

The objectives of the study were to evaluate the clinicopathological profile of patients of lung carcinoma in a tertiary care hospital and to correlate between cytological and histological diagnoses of the tumours.

\section{MATERIALS AND METHODS}

A study of patients presenting with lung mass between March 2016 and February 2017 (one year) was performed. Guided fine needle aspiration cytology (FNAC) was performed in each case and core needle biopsy was done whenever feasible. The clinical records of the patients were reviewed in relation with age, sex, smoking habits, radiographic findings and cytologic diagnoses. Core needle biopsy findings were also recorded when available. It was a descriptive type of study. 
A total of 72 cases were studied. A detailed clinical history with investigations was collected from each patient using a proper data collection form. Approval from ethics committee was taken, consent from all the patients or guardian of the patient was taken, confidentiality of the findings of the patients was ensured and data was utilised purely for academic purpose.

After step-wise tissue processing, embedding, blocking and microtomy of the available core needle biopsy specimens, haematoxylin and eosin ( $\mathrm{H}$ and $\mathrm{E}$ ) stained sections were prepared for light microscopic examination in each case. The cytology smears prepared from the lung SOL were stained with both Leishman Giemsa stain and Papanicolaou stain followed by careful examination under light microscope.

The data was compiled using Microsoft Word Excel 2007. Kappa statistic test and percentage agreement was done and Kappa coefficient was derived. Kappa coefficient value $>0.75$ denotes excellent agreement, value between 0.4 and 0.75 denotes good agreement and value $<0.4$ denotes poor agreement.

\section{RESULTS}

A total of 72 patients were included. The ratio of male-tofemale patients was 6: 1 . The age of the patients ranged between 41 and 82 years with preponderance in age group of 61 - 70 years $(44.4 \%)$ (see Table 1 ). Non-neoplastic lesions were found in $8(11.11 \%)$ and neoplastic lesions in 64 $(88.88 \%)$ cases. The distribution of neoplastic lesions is being illustrated by pie diagram (Figure 1 ).

Fifty $(78.1 \%)$ patients of lung carcinoma were smokers. The right lung was involved in 38 cases (60\%), the left in 19 cases $(30 \%)$ and both lungs were involved in 7 cases $(10 \%)$. Core needle biopsy was undertaken in 43 cases. Consistent histopathologic findings were obtained in 40 cases and did not match in 3 cases. Kappa statistic test and percentage agreement was done using Table 2 and Kappa coefficient was derived. Overall percentage agreement observed between FNAC and core needle biopsy was 93\%. Agreement expected by chance for presence of disease diagnosed by both of these two modalities was 40 . Agreement expected by chance for absence of disease diagnosed by both of these two modalities was 0 . Total percentage agreement by chance between these two modalities was $40 \%$. Kappa coefficient was found to be 0.8 , which is consistent with excellent agreement (as $>0.75$ ).

Relevant findings of this study are also being depicted with images (Figure 2).

\begin{tabular}{|c|c|c|}
\hline Age in Years & Frequency & Percent \\
\hline $41-50$ & 8 & 11.1 \\
\hline $51-60$ & 19 & 26.4 \\
\hline $61-70$ & 32 & 44.4 \\
\hline $71-80$ & 10 & 13.9 \\
\hline $81-90$ & 3 & 4.2 \\
\hline Total & $\mathbf{7 2}$ & $\mathbf{1 0 0 . 0}$ \\
\hline Table 1. Frequency Distribution Table showing \\
Distribution of Lung SOL among Different Age Groups \\
\hline
\end{tabular}

\begin{tabular}{|c|c|c|c|c|c|}
\hline & \multicolumn{2}{|c|}{ FNAC } & \multirow[b]{2}{*}{ Total } & \multirow[b]{2}{*}{$\begin{array}{c}\text { Kappa } \\
\text { Coefficient }\end{array}$} \\
\hline & & \begin{tabular}{|c|} 
Diagnosed \\
Disease
\end{tabular} & \begin{tabular}{|c|} 
Could not \\
Diagnose \\
Disease
\end{tabular} & & \\
\hline \multirow{2}{*}{$\begin{array}{c}\text { Core } \\
\text { Needle } \\
\text { Biopsy }\end{array}$} & \begin{tabular}{|c|} 
Diagnosed \\
disease
\end{tabular} & 40 & 3 & 43 & \multirow{3}{*}{$\begin{array}{c}0.8 \\
\text { (excellent } \\
\text { agreement } \\
\text { as }>0.75 \text { ) }\end{array}$} \\
\hline & $\begin{array}{c}\text { Could not } \\
\text { diagnose } \\
\text { disease }\end{array}$ & 0 & 0 & 0 & \\
\hline & Total & 40 & 3 & 43 & \\
\hline
\end{tabular}

Table 2. Table for Kappa Statistics and Percentage Agreement between FNAC and Core Needle Biopsy in Cases of Lung SOL where both the Modalities were Done

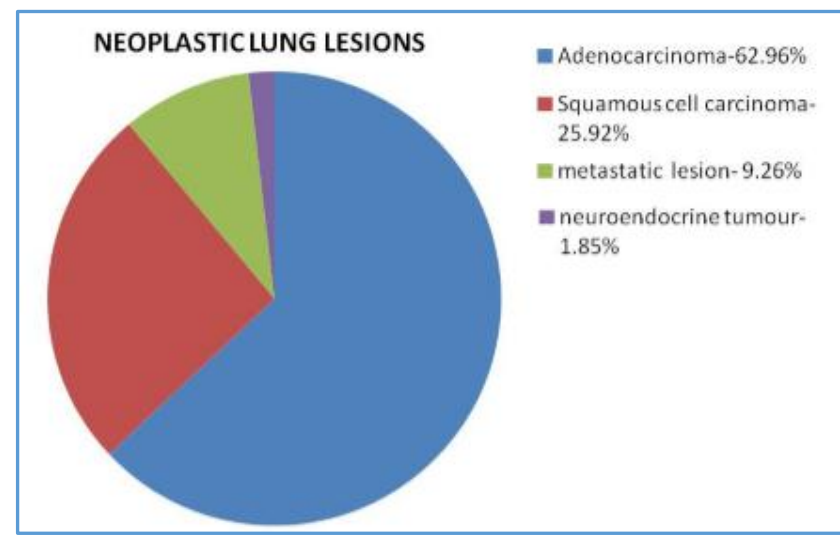

Figure 1. Pie Diagram showing Distribution of various Neoplastic Lung SOL in this Study

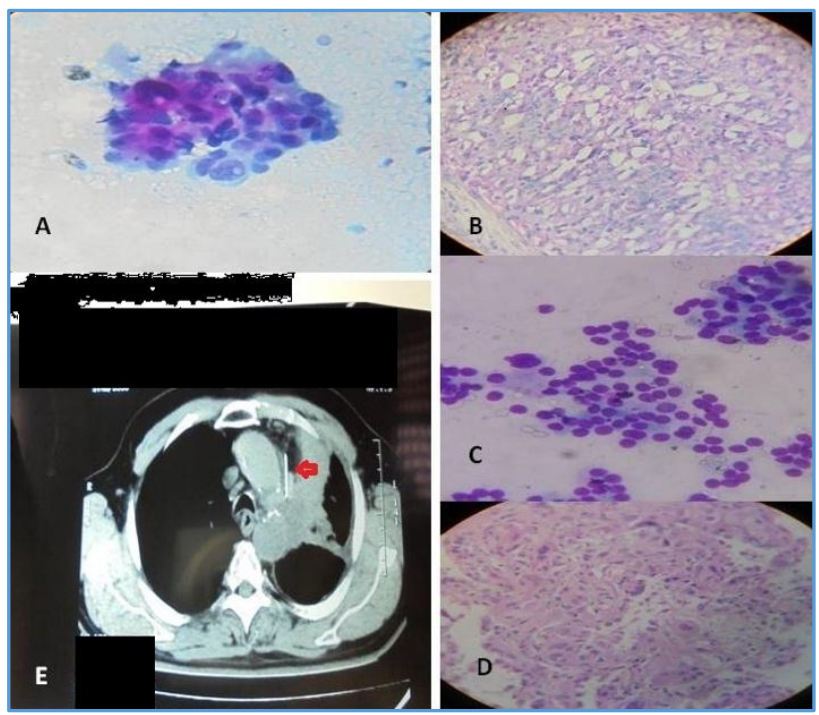

Figure 2- A- Case of Squamous Cell Carcinoma Lung (Cytology). B-Corresponding Histopathology (H and E Stain, 100X). C-Case of Adenocarcinoma Carcinoma Lung

(Cytology). D-Corresponding Histopathology (H and E

Stain, 100X). E- CT Scan Chest showing a Lung SOL Marked by a Core Biopsy Needle shown by Red Arrow

\section{DISCUSSION}

In this study, the male-to-female ratio was $6: 1$. Reddy et al found a male-to-female ratio of 4: 1 in their study.[6] Kashyap et al reported a ratio of 6.1: 1.[7] Age range in our study was 41 to 82 years. Thippanna et al noticed a comparable age distribution.[8] Commonest radiological lesion according to this study was a space occupying lesion. In this study, right lung is found to be more frequently involved than left lung. Khan et al observed 63\% lesions in the right lung. ${ }^{[9]}$ FNAC 
done under CT is the investigation of choice for peripherally situated lesions.

Out of the 43 cases in whom core needle biopsy was done, the histologic and cytologic findings match in 40 cases. It did not match in 3 cases. Cytology was reported as inflammatory/ haemorrhagic. CT scan revealed the mass was almost entirely necrotic. Core needle biopsy of these cases showed areas of adenocarcinoma. So, FNAC was found to be highly useful in diagnosis of lung mass as shown by previous studies also.[10,11] Böcking et al compared fine needle aspiration cytology (FNAC) and punch biopsy (PB), and found that the overall sensitivities of the biopsy methods were equal.[12] They concluded that FNAC should be the method of choice in pulmonary and hilar lesions, because of the similar diagnostic accuracy. Mondal et al found FNAC to be superior in categorising lung neoplasms.[13]

The pattern of lung cancer has been changing in the West. Lung cancer is being increasingly diagnosed in women and adenocarcinoma has overtaken SCC as the most common histological cell type.[14] In this study also, among the neoplastic lesions adenocarcinoma was diagnosed in 34 cases (62.96\%) and squamous cell carcinoma in 14 cases $(25.92 \%)$.

Smoking was the most common predisposing factor which included cigarettes, beedis, hookah, etc. Similar observation has been reported by other Indian studies also.[15-19] According to this study, 50 (78.1\%) patients of lung carcinoma were smokers. Thus, smoking constitutes an important yet avoidable cause of lung carcinoma.

Thus, although squamous cell carcinoma and small cell lung cancer were more common histologic subtypes of lung cancer in the beginning of the smoking-related cancer epidemic, latest studies have constantly reported the preponderance of adenocarcinoma, which is now considered as the most common histologic type of lung cancer.[20-24] The findings of our study was also concordant.

\section{CONCLUSION}

Smoking constitutes an important, yet avoidable cause of lung carcinoma. The delineation of clinicopathologic profile of patients of a particular area is essential for determination of preventive and therapeutic strategies. FNAC can be considered as a highly useful tool for diagnosis of lung mass.

\section{REFERENCES}

[1] Rawat J, Sindhwani G, Gaur D, et al. Clinicopathological profile of lung cancer in Uttarakhand. Lung India 2009;26(3):74-6.

[2] Karnath B. Smoking cessation. Am J Med 2002;112(5):399-405.

[3] Carr DT, Holoye PY, Hong WK. Bronchogenic carcinoma. In: Murray JF, Nadal JA. eds. Text book of respiratory medicine. $2^{\text {nd }}$ edn. Philadelphia: WB Saunders Company 1994:1528-96.

[4] Beckett WS. Epidemiology and etiology of lung cancer. Clin Chest Med 1993;14(1):1-15.

[5] Sen U, Sankaranarayanan R, Mandal S, et al. Cancer patterns in eastern India: the first report of the Kolkata cancer registry. Int J Cancer 2002;100(1):8691.
[6] Reddy DB, Prasanthamurthy D, Satyavathi S. Bronchogenic carcinoma: a clinico-pathological study. Indian J Chest Dis 1972;14(2):86-9.

[7] Kashyap S, Mohapatra PR, Nagi RS. Pattern of primary lung cancer among Bidi smokers in north-western Himalyan region of India. Lung Cancer 2003;41(Suppl 2):S111.

[8] Thippanna G, Venu K, Gopalkrishna V, et al. A profile of lung cancer patients in Hyderabad. J Indian Med Asso 1999;97(9):357-9.

[9] Khan NA, Afroz F, Lone MM, et al. Profile of lung cancer in Kashmir, India: a five year study. Int J Chest Dis Allied Sci 2006;48(3):187-90.

[10] Madan M, Bannur H. Evaluation of FNAC in the diagnosis of lung lesions. Turk J Pathol 2010;26(1):16.

[11] JayaShankar E, Pavani B, Chandra E, et al. Computed tomography guided percutaneous thoracic: Fine needle aspiration cytology in lung and mediastinum. J Cytol Histol 2010;1(3):107-10.

[12] Böcking A, Klose KC, Kyll HJ, et al. Cytologic versus histologic evaluation of needle biopsy of the lung, hilum and mediastinum. Sensitivity, specificity and typing accuracy. Acta Cytol 1995;39(3):463-71.

[13] Mondal SK, Nag D, Das R, et al. Computed tomogram guided fine-needle aspiration cytology of lung mass with histological correlation: a study in eastern India. South Asian J Cancer 2013;2(1):14-18.

[14] Quinn D, Gianlupi A, Broste S. The changing radiographic presentation of bronchogenic carcinoma with reference to cell type. Chest 1996;110(6):1474-9.

[15] Jindal SK, Malik SK, Malik AK, et al. Bronchogenic carcinoma: a review of 150 cases. Indian J Chest Dis Allied Sci 1979;21(2):59-64.

[16] Notani P, Sanghvi LD. A retrospective study of lung cancer in Bombay. Br J Cancer 1974;29(6):477-82.

[17] Jindal SK, Malik SK, Datta BN. Lung cancer in Northern India in relation to age, sex and smoking habits. Eur J Respir Dis 1987;70(1):23-8.

[18] Jindal SK, Malik SK, Dhand R, et al. Bronchogenic carcinoma in Northern India. Thorax 1982;37(5):3437.

[19] Behera D, Balamugesh T. Lung cancer in India. Indian ] Chest Dis Allied Sci 2004;46(4):269-81.

[20] Alberg AJ, Samet JM. Epidemiology of lung cancer. Chest 2003;123(1):21S-49S.

[21] Valaitis J, Warren S, Gamble D. Increasing incidence of adenocarcinoma of the lung. Cancer 1981;47(5):10426.

[22] Vincent RG, Pickren JW, Lane WW, et al. The changing histopathology of lung cancer: a review of 1682 cases. Cancer 1977;39(4):1647-55.

[23] Charloux A, Quoix E, Wolkove N, et al. The increasing incidence of lung adenocarcinoma: reality or artefact? A review of the epidemiology of lung adenocarcinoma. Int J Epidemiol 1997;26(1):14-23.

[24] Travis WD, Travis LB, Devesa SS. Lung cancer. Cancer 1995;75(Suppl 1):191-202. 